УДК 316.354:355

$10.17213 / 2075-2067-2021-4-23-35$

\title{
МЕТОДОЛОГИЧЕСКИЙ КОНСТРУКТ ИССЛЕДОВАНИЯ МЕНЕДЖЕРИСТСКИХ ИНСТРУМЕНТОВ ОБЕСПЕЧЕНИЯ ЭФФЕКТИВНОСТИ МУНИЦИПАЛЬНОГО УПРАВЛЕНИЯ
}

\author{
(C) 2021 г. А. В. Дятлов, В. В. Ковалев, Я. А. Асланов
}

\section{Южный федеральный университет, г. Ростов-на-Дону, Россия}

Целью исследования выступает разработка конщепции для изучения инструментов государственного менеджеризма в практике повышения эффективности российского муниципального управления.

Методологическая база исследования формируется в рамках теории рационального выгора Дж. Коулмана. В ее основе лежит идея о трех формах капитала - физического, человеческого и сочиального, которые в процессе выбора наиболее рациональной альтернативы сочиального действия трансформируются в набор ресурсов, используемых актором в качестве средства достижения иели.

Результаты исследования. Разработана теоретическая модель изучения инструментов государственного менеджеризма, реализуемых для повымения эффекктивности муниципального управления. В качестве исходных тезисов, в рамках которых раскрываются указанные менеджеристские инструменты, взяты три положения: 1) снижение государственного финансирования там, где обнаруживается низкий рост показателей; 2) стимулирование предпринимательской активности в некоммерческом секторе; 3) замена специалистов-управленцев эффективными менеджерами. После проведения соответствующих операщий с базовыми понятиями в итоге получен набор признаков, формирующих содержательный объем менеджеристских инструментов, применяемых непосредственно в системе муниципального управления. Формулировка и описание этих инструментов в ракурсе повышения эффективности органов местного самоуправления позволит выйти на финальный этап создания менеджеристской модели муниципального управления.

Перспективы дальнейших исследований авторы видят в проведении эмпирического исследования с иелью практического использования разработанной теоретической модели. Предметно исследование будет направлено на такие аспекты деятельности органов местного самоуправления, как работа на показатели, управление в форме оказания услуг, структурная перестройка органов власти, результативность взаимодействия с гражданскими активистами и бизнес-сообществами.

Ключевые слова: государственный менеджеризм; муниципальное управление; эффективность муниципального управления; эмпирические индикаторы; менеджеристские инструменты; муниципальное самоуправление.

1 Статья выполнена в рамках реализации гранта РФФИ, проект №21-011-31846/21 «Менеджеристские инструменты обеспечения эффективности муниципального управления (на примере муниципальных образований Южного федерального округа)». 


\title{
METHODOLOGICAL CONSTRUCT OF THE STUDY OF MANAGERIAL TOOLS FOR ENSURING THE EFFECTIVENESS OF MUNICIPAL MANAGEMENT
}

\author{
(C) 2021 A. V. Dyatlov, V. V. Kovalev, Ya. A. Aslanov
}

Southern Federal University, Rostov-on-Don, Russia

The aim of the research is to develop a concept for studying the tools of state managerism in the practice of improving the efficiency of Russian municipal administration.

The methodological basis of the research is formed within the framework of the theory of rational choice of J. Coleman. It is based on the idea of three forms of capital - physical, human and social, which in the process of choosing the most rational alternative to social action are transformed into a set of resources used by the actor as a means to achieve the goal.

The results of the study. A theoretical model for studying the tools of state managerism implemented to improve the efficiency of municipal management is developed. As the initial theses, within the framework of which these managerial tools are disclosed, three provisions are taken: 1) reduction of state funding where there is a low growth in indicators; 2) promotion of entrepreneurial activity in the non-profit sector; 3) replacement of managerial specialists with effective managers. After performing the corresponding operations with the basic concepts, as a result, a set of features is obtained that form the content volume of managerial tools used directly in the municipal management system. The formulation and description of these tools from the perspective of improving the efficiency of local self-government bodies will allow us to reach the final stage of creating a managerial model of municipal management.

The authors see the prospects for further research in conducting an empirical study with the aim of practical use of the developed theoretical model. The research will focus on such aspects of the activities of local self-government bodies as work on indicators, management in the form of service delivery, structural restructuring of government bodies, and the effectiveness of interaction with civil activists and business communities.

Key words: state managerism; municipal management; efficiency of municipal management; empirical indicators; managerial tools; municipal self-government.

Введение. С 2005 года в Российской Федерации проводится широкомасштабная административная реформа. Ее началом стало Распоряжение Правительства России от 25 октября 2005 г. №1789-р, которым одобрен пакет документов, обеспечивающих реализацию принципиально новой концепции государственного управления. Она основывается на нескольких основополагающих принципах: управление по результатам, управление в форме оказания услуг, строгая формализация деятельности государственных служащих посредством принятия административных регламентов, оптимизация избыточных и дублирующих управленческих структур, широкое внедрение аутсорсинга, транспарентность власти и ее сотрудничество со структурами гражданского общества.

В качестве ориентира был взят опыт проведения подобных же реформ в странах Западной Европы и Северной Америки. Еще в начале 90-х годов прошлого века он получил название в формирующемся по итогам его реализации научном дискурсе «новое государственное управление» или «государственный менеджеризм». Он был воспринят по аналогии из сферы корпоративного управления, где менеджеризм сложился как идеология и одновременно управленческая мо- 
дель, направленная на усиление рациональных начал при управлении организацией.

Менеджеризм стал применяться в управленческих практиках в целях повышения их эффективности. Этот же побудительный мотив доминировал у инициаторов российской административной реформы. Практически сразу вслед за изменением основных начал государственного управления федеральный законодатель инициировал и трансформацию муниципального управления. Важный шаг на пути этого процесса - переход оценки эффективности управленческих результатов на измеряемые количественные показатели. Еще одна важная инновация - изменение правил легитимации вступления в должность главы муниципального образования. С 2 февраля 2015 г., невзирая на сохранение иных нормативных альтернатив, он, как правило, избирается на контрактной основе представительным органом власти муниципалитета.

Благодаря двум этим инновациям муниципальная власть фактически потеряла содержательные отличия от государственной.

Данная практика является результатом переноса института, сложившегося в иной социокультурной и экономической среде. Это порождает ряд вопросов. Во-первых, возникает проблема правомерности трансфера управленческих технологий, пусть и доказавших свою состоятельность, но обеспечивающих эффективность в корпоративных коммерческих организациях. Если публичное управление имеет фундаментальные различия относительно управления корпоративного, то не приведет ли искусственное навязывание новых институциональных правил к росту имитационных практик в работе муниципальных органов власти? Во-вторых, исторически муниципальные органы власти в западной политико-управленческой традиции сложились не только как низовой уровень публичного управления, но и в образе особой формы самоорганизации населения территориальных пространств. Именно в таком качестве местное самоуправление воссоздавалось на постсоветском пространстве после распада СССР. Однако есть вероятность, что реализация принципов государственного менеджеризма может привести к деформации механизмов самоорганизации граждан. В связи с этим возникает проблема: в чем может проявляться указанная деформация и не станет ли новая модель муниципального управления источником развития иждивенческо-патерналистских настроений, препятствующих реальному участию граждан в инициативном решении вопросов местного значения? В-третьих, менеджеризм был перенесен в сферу российского публичного управления не только из корпоративной среды, но и из другой социокультурной и социально-политической реальности. Не станет ли это препятствием для его результативного использования в российском обществе, где иные стартовые условия и возможности?

Комплексный ответ на три поставленных вопроса позволит дать достижение следующей цели: разработка концепции для изучения инструментов государственного менеджеризма в практике повышения эффективности российского муниципального управления.

Методологические основы исследования. Методологические основы выстроим в опоре на теорию рационального выбора. Избрание данной парадигмы объясняется как особенностями ее теоретической конструкции, так и особым потенциалом, который можно использовать в целях исследования предметного пространства. Указанное направление на данный момент является одним из наиболее оптимальных для применения в качестве методологии в социологических исследованиях. Ее концептуализация стала удачным выходом из спора между сторонниками классической и постнеклассической социологии о целях социологии и способности отражать социальную реальность.

В предметном ракурсе классической парадигмы акцент традиционно делался на изучении оснований социальной устойчивости, а в методологическом контексте - на поисках методов и инструментов, способных зеркально отразить социальную реальность. В постнеклассической парадигме вектор исследовательского интереса в предметном плане переместился на изучение индивида и малых групп, а в методологическом на интерпретацию индивидуальных траекторий социальных акторов. Подобные акценты возникли неслучайно. Классическая социология появилась в те времена, когда основная масса социальных акторов проживала в ус- 
ловиях традиционного общества. Для него характерна устойчивая система ценностей и нормативных моделей поведения, различия по которым можно было четко привязать к особенностям стратификационной системы. Распад традиционного общества привел к индивидуализации сознания и возникновению сначала неклассической, а затем и постнеклассической социологии, кульминацией развития которой стала постмодернистская теория. Спор между сторонниками двух метапарадигм, по сути, сводился к степени ограничений у акторов индивидуального выбора социальных моделей поведения. Если классики настаивали на том, что индивид попадает в институциональную матрицу и его выбор соответственно предопределен сложившимися социальными шаблонами, то их оппоненты говорили о безграничных вариациях и полной непрогнозируемости процесса социальной коммуникации.

Теория рационального выбора оказалась своеобразным компромиссом между двумя подходами. С точки зрения ее сторонников, в современном обществе институциональные матрицы по-прежнему сохраняют свое значение, но, в отличие от общества традиционного, для достижения какой-то одной цели существуют альтернативные варианты их выбора, что обеспечивается появившейся в современном обществе свободой в действиях социальных акторов, отказом от следования жестким детерминантам и навязанным стратегиям социального поведения. Именно в этом и проявляются особенности указанного подхода как теории, методологически наиболее приемлемой для изучения общества современного типа.

Анализируемая парадигма содержит в себе множество нюансов и аспектов. Она разрабатывалась целой плеядой социологов и экономистов. Наше исследование будет концептуально опираться на идеи, изложенные в одной из последних статей в наследии Дж. Коулмана «Капитал социальный и человеческий» [1]. Социолог объясняет выбор альтернатив социальными характеристиками имеющегося у акторов трех форм капитала: физического, человеческого и социального. К физическому относятся материальные ресурсы и формальные нормы. Под человеческим капиталом понимаются ценности, моти- вы, интересы, то есть некие побудительные факторы, проистекающие из индивидуальных особенностей конкретного социального актора. И, наконец, социальный капитал представляет собой совокупность устойчивых структур неформальных норм, социальных связей, знакомств и т.п.

В контексте рационального выбора эти три типа капитала выступают в роли набора ресурсов, обеспечивающих возможность достижения индивидуальных целей, определяемых для себя социальными акторами. При этом, как настаивает Дж. Коулман, акторы могут быть лицами как физическими, так и корпоративными [2], что для нас представляется удобным для изучения организационных структур, возникающих в системе муниципального управления. Очевидно, что степень рациональности совершаемого выбора оценивается через валидность поставленной цели относительно имеющихся у социальных акторов ресурсов для ее достижения. Предполагая проводить анализ эффективности такой разновидности профессиональной деятельности, как муниципальное управление, мы далее намерены исследовать способность к достижению целей с имеющимся в распоряжении местных органов власти объемом ресурсов.

Операционализация базовых понятий (муниципальное управление, эффективность муниципального управления, государственный менеджеризм, менеджеристские инструменты)

Мунищипальное управление. Анализ этого понятия построим на определении предметно-семантического значения терминов «муниципальный» и «управление». Первый из них имеет двойственную оценку среди ученых. Согласно одной позиции, муниципальный проистекает от латинского «mūnicipium», что означает «вольный город». В этом качестве происходит отождествление слов «муниципальный» и «местный», независимо от того, к какому существительному они прилагаются [3]. Но есть и отличный взгляд, сторонники которого настаивают на содержательном различении приведенных выше слов. Дифференциация строится на исторически сложившихся в практике употребления значениях. Под местным обычно понимается 
некое самоорганизованное на определенной территории сообщество, а муниципальное наделяется формально-правовым смыслом. Отсюда выводятся устойчивые сочетания, в том числе «муниципальное управление» [4]. С нашей точки зрения, придавать словам «муниципальный» и «местный» различное значение принципиально неверно. От такого подхода один шаг до признания муниципальной власти и, соответственно, управления особой разновидностью власти государственной. Но это противоречит Конституции и сложившемуся дискурсу о том, что местное самоуправление действует на началах автономии от государства. Иными словами, термин «муниципальный» так же, как «местный», должен увязываться с процессами самоорганизации территориальных сообществ для решения вопросов местного значения.

Термин «управление» среди ученых, как правило, не вызывает существенных разночтений. Его понимание отождествляется с особым видом публичной деятельности, которая предполагает постановку целей, приискание ресурсов для их достижения, формирование мотивации у субъектов управленческой деятельности, а также осуществление контроля над ними [5]. Однако далеко не так все просто в отношении понятия «муниципальное управление». В значительной степени проблемы проистекают из расхождений в оценках слов «местный» и «муниципальный», о чем мы уже писали. Именно эти расхождения обусловили возможность выделить, по меньшей мере, три основных подхода к анализируемому понятию. Согласно первому муниципальное управление отражает в себе запрос на демократизацию низового уровня публичного управления. В таком проявлении акценты делаются не только на традиционных признаках, типичных для управления, но и на широком участии территориальных сообществ в управленческой деятельности [6]. Ученые, придерживающиеся второго подхода, настаивают на формализации понятия с позиции юридических категорий и фактически отождествляют его с государственным управлением [7]. И, наконец, в рамках третьего подхода говорится об особом качестве муниципального управления в связи с нормативными отсылками о делегировании исполнения органами муни- ципальной власти полномочий в сфере местного самоуправления, предписанных по законодательству региональной или федеральной власти [8]. Нам ближе по содержанию первый подход. Второй мы не принимаем потому, что разделение понятий «муниципальное самоуправление» и «муниципальное управление» не выхолащивает из последнего его непосредственной связи с территориальными сообществами, а отражает в большей степени дань исторической традиции. Что касается третьего подхода, то наделение муниципальных органов власти государственными полномочиями не меняет их сущности.

С учетом представленной трактовки мы можем предложить следующее инструментальное определение термина «муниципальное управление». Это особая разновидность публичной деятельности, которая реализуется органами власти местного самоуправления в пределах их компетенщии и ресурсных возможностей и ориентирована на достижение иелей, актуально значимых для определенного территориального сообщества (муниципального образования). В качестве дополнительного пояснения отметим, что поскольку термин «муниципальный» содержит в нашем понимании элементы как прямой, так и представительной демократии, включая формы непосредственного осуществления населением местного самоуправления, то муниципальное управление реализуется посредством самого широкого спектра социальных акторов: сити-менеджера, администрации, депутатского корпуса, структур гражданского общества, в том числе предпринимательских сообществ. При переходе к эмпирическим исследованиям мы планируем оценить ресурсный потенциал каждого из указанных социальных акторов с точки зрения возможности обеспечить достижение цели в контексте сделанного рационального выбора.

Следующее понятие - «эфффективность муницииального управления». Эффективность принято оценивать с позиции использования ресурсов, поэтому заявленная выше методология будет нами задействована применительно к данному понятию с прицелом на максимально близкий выход на предметное поле исследования.

Как научная категория эффективность была впервые обоснована Д. Рикардо, трак- 
товавшим его через призму соотношения затрат и результата [9]. Длительное время она не подвергалась какой-либо критике, пока данное понятие не стали применять к оценке процессов и результатов, не имеющих непосредственного отношения к экономике. В результате этого дискурсивное пространство, сложившееся в связи с обсуждением спорных вопросов, расширилось в самом конце XX века за счет представителей других общественных наук: социологов, политологов, философов, педагогов и психологов. По итогам дискуссии, развернувшейся в междисциплинарном ракурсе, понимание эффективности оформилось в пределах трех подходов.

Первая группа ученых осталась на классических позициях, рассчитывая эффективность через корреляцию полученного результата и затраченных на его достижение ресурсов [10]. Другое понимание эффективности приравнивается к достижению результата вне зависимости от производной «затраты». Сторонников такого подхода объединяет научная идентичность, выходящая за пределы экономической предметности [11]. В качестве основного аргумента постулируется невозможность количественных измерений результатов деятельности в неэкономических институтах. Указанный подход едва ли можно назвать решением возникших затруднений. Это в большей степени похоже на аргументированный отказ их решать. Существенным достижением состоявшейся дискуссии мы считаем выработку третьей модели эффективности, в соответствии с которой она оценивается в позитивных коннотациях, если имеет место достижение заведомо заявленной цели и осуществлено это при таких ресурсных затратах, которые с точки зрения устоявшихся общепринятых практик признаются разумными, общепринятыми и обоснованными [12].

С учетом когнитивных рамок третьего подхода рабочее определение эффективности муниципального управления можно сформулировать следующим образом: достижение иелей, поставленных перед местными органами власти, осуществленное при таких ресурсных затратах, которые с точ$к и$ зрения устоявшихся общепринятых практик признаются разумныли, общепринятыми и обоснованными.
Несмотря на то, что в подобном понимании мы привязываемся к субъективным оценкам, именно данный подход будет взят нами за основу при исследовании эффективности муниципального управления. Преодоление субъективизма или, если поставить вопрос иначе, трансформацию субъективных оценок эффективности в объективные результаты оценки работы органов муниципального управления можно реализовать в процессе применения эмпирических методов исследования, присущих социологической науке. Здесь возможны корреляции как с экспертными суждениями (качественные методы), так и с пожеланиями населения муниципальных образований (количественные методы).

Таким образом, согласно нашей концепции объектом измерения эффективности в муниципальном управлении будут три аспекта: во-первых, достижение социально значимой цели; во-вторых, наличие ресурсов для ее достижения; в-третьих, разумность траты ресурсов («цена вопроса»).

Теория рационального выбора дает установку на то, что деятельность социальных акторов основывается на целеполагании. Это характерно как применительно к индивидуальным агентам, так и в отношении корпоративных, поэтому рациональность совершаемых ими выборов и эффективность полученных от их деятельности результатов следует соотносить с декларируемыми целями. В пределах предмета исследования нужно ориентироваться на сформулированное выше понимание муниципального управления. В нашей интерпретации оно обращено на решение вопросов местного значения с участием широких сфер общественности конкретной территории. С учетом их специфики цель для муниципального управления можно определить как повышение качества жизни населения муниципальных образований. Само муниципальное управление рассматривается как разновидность публичной деятельности. Следовательно, оно направлено на общественно значимые цели. Это означает, что категория целеполагания должна быть центральной при оценке эффективности муниципального управления. Характер цели, ее достижимость и достигнутость - это основные переменные для оценки эффективности муниципального управления. 
В пределах применяемой методологии очень важное значение имеют ресурсы. В теории рационального выбора Дж. Коулмана под ними понимаются три разновидности капитала: физический, человеческий и социальный. Их объективная оценка способна обеспечить понимание относительно достижимости поставленной цели, что позволит установить реальную, а не мнимую рациональность сделанного выбора. Из этого проистекает особая необходимость сделать описание указанных форм капитала в контексте потенциальной возможности повысить эффективность муниципального управления.

Под физическим капиталом надлежит понимать некую предзаданность материальных ресурсов и заведомо определенные экзогенными акторами (здесь - государством) правила игры, которые невозможно самостоятельно изменить. Конкретно для муниципального управления это, во-первых, формальные нормы (легитимация власти, местные налоги, законодательство о бюджете, правила использования муниципальной собственности, но, в первую очередь, нормативно-правовые акты, устанавливающие легальные показатели достижения эффективности); во-вторых, материальные возможности конкретной территории (водные ресурсы, качество земель, состояние ЖКХ, дорог, придомовой территории и т.п.). Эти ресурсы должны оцениваться с точки зрения их достаточности для достижения поставленной цели.

Другая форма капитала - человеческий - выступает критерием анализа социальных качеств акторов, осуществляющих совместную целедостижительную деятельность. В сфере муниципального управления действуют такие группы акторов, как уже упоминавшиеся выше сити-менеджер, местная администрация, депутатский корпус, структуры гражданского общества и квазисубъект, население территориальных сообществ. Применительно к ним следует учитывать, могут ли содействовать эффективному управлению свойственные им ценности, мотивы, интересы, стереотипные установки, иными словами, все, что образует исторически сформировавшуюся социокультурную матрицу, определяющую программы социального поведения. Особо пристальное внимание нужно уделить соответствию челове- ческого капитала предписанным институциональным правилам.

Третья форма капитала - сочииальный. Если первые две (прежде всего, физический капитал) определяют жесткие ограничительные рамки и являются либо продуктом экзогенного воздействия на муниципальное управление (создание формальных правил государством), либо результатом исторического развития (сложившиеся у социальных акторов стереотипы, паттерны, социальные установки), то третья форма капитала выражает субъектную волю социальных акторов. Она реализуется в рамках неформальных ограничений, вырабатываемых самими же социальными акторами. Дж. Коулман определяет три группы условий, при которых социальный капитал будет действовать как эффективная ресурсная база. Это: 1) исполнение обязательств, соответствие ожиданий получаемому результату, надежность структуры норм; 2) наличие информационных каналов; 3) эффективность санкций к девиантам. Они применимы к любым видам социального действия и, надо полагать, такой ее разновидности, как муниципальное управление.

Третий объект измерения эффективности муниципального управления - обоснованность траты ресурсов («цена вопроса»). Поскольку отраслевой основой исследования является социология, а не экономика или юриспруденция, то делать финансовые расчеты или устанавливать состав преступления мы не станем. Данный аспект отдан «на откуп» социальным акторам (выбранной совокупности респондентов). Их консолидированная позиция, полученная через опросные методы, будет определять с учетом наших интерпретаций и сопоставлений с выделенными выше двумя другими аспектами анализа эффективности разумность, общепринятость и обоснованность затрат ресурсов на достижение целей муниципального управления.

Следующее понятие нашего методологического конструкта — «государственный менеджеризм».

Ввод этого понятия в структуру методологического конструкта резко сужает предметное пространство. Совершенно очевидно, что мы не ставим перед собой метазадачу досконально исследовать все выделенные аспекты эффективности муниципального уп- 
равления. Нас интересует их роль сквозь призму обеспечения эффективности в ходе применения в практике муниципального управления менеджеристских инструментов. Описанные выше три аспекта будут оцениваться с позиции воздействия на них реализуемых в муниципальном управлении менеджеристских инструментов.

Для начала разберемся с данным понятием, т.к. в его определении имеются некоторые нюансы. Государственный менеджеризм принят на вооружение правящими элитами западных стран в 80-е годы XX в. Его использование нацеливалось на решение двух основных задач: разгрузить бюджет в условиях усиления давления на государственные финансы со стороны общественного сектора и повысить управленческую эффективность за счет внедрения рыночных инструментов в управление. Эти две позиции заложим в конструкцию авторского определения. Государственный менеджсеризм - это идеология, используемая в иелях повышения эффективности управления общественныли проиессами, что достигается благодаря переносу управленческих принципов, выработанных в коммерческих организащиях, в область публичного управления. Одной из разновидностей последнего мы считаем муниципальное управление.

Дискурс о государственном менеджеризме имеет не очень продолжительную историю. На Западе это понятие изучается с конца 80-х гг. прошлого столетия $[13,14$, 15]. В России запрос на оценку управленческих практик менеджеризма пришел в науку на несколько лет позже. Это неудивительно, т. к. сами реформы соответствующей направленности начали проводиться на четверть века позднее. Поэтому при характеристике дискурса, сложившегося в управления вокруг менеджеризма, очень важно понимать, что в значительной мере отечественные ученые предпринимают попытки не столько разработать новые управленческие теории, отражающие доселе не известные грани менеджеризма, сколько понять, как эти теории работают в российских условиях и какие оригинальные особенности политика «нового государственного управления» приобретает в государственном управлении нашей страны. И, что показательно, специальных работ в предметности муниципального управления практически нет. Есть отдельные исследования по направлениям менеджеристской политики в области реализации муниципальной власти: анализ показателей эффективности или институциональные основы функционирования сити-менеджмента, но необходимо отметить, что отсутствует целостная теория применения менеджеризма в муниципальном управлении.

Анализ зарубежных и отечественных исследований позволил прийти к выводу, что в основу понимания менеджеризма в сфере муниципального управления может быть положено три базовых признака: 1) децентрализация управления; 2) широкое использование рыночных начал в управленческой деятельности; 3) применение количественных показателей как индикаторов оценки эффективности управления.

Децентрализащия мунищипального управления проявляется в первую очередь в форме отказа от применения в управленческой деятельности принципов классической бюрократии. Происходит такое перераспределение функций и прерогатив, при котором основные полномочия перемещаются на нижние этажи пирамиды управления, включая выстраивание прочных связей с институтами гражданского общества и бизнеса, сотрудничающего с органами власти на началах муниципально-частного партнерства. При подобных условиях муниципальная власть рассматривается в роли публичного агента, ответственного за перераспределение ресурсов между различными группами акторов, необходимых для повышения качества жизни населения муниципальных образований. Достижение данной цели обеспечивается действием в правовом пространстве Российской Федерации целой группы формальных норм, поддерживающих социальную активность территориальных сообществ в решении вопросов местного значения.

Широкое использование рыночных начал в муниципальном управлении выражается в отождествлении публичного управления с управлением коммерческой организацией. Местные органы власти по формальным признакам начинают функционировать в образе квазикоммерческой структуры, оказывающей населению возмездные или безвозмезд- 
ные услуги. В них разрабатываются стратегические планы развития, применяется система менеджмента качества, допускается коммерческая деятельность, не противоречащая функциональной направленности, в основу оценки закладываются рыночные принципы. Эффективность работы местных органов власти определяется по легко просчитываемым количественным индикаторам, что обуславливает формализацию учета результатов деятельности.

Применение количественных показателей как индикаторов оченки эффективности муниципального управления. Этот признак во многом является сердцевиной, ядром менеджеризма, проявляясь в образе универсальной категории во всех социальных институтах, затронутых менеджеристской идеологией. Их роль сводится к некоей имитации производственного процесса, результативность которого оценивается по количеству произведенных работ и услуг. Мы специально делаем акцент на слове «имитация», т.к. в реальных рыночных условиях товары и услуги оцениваются потребителями через договор купли-продажи в режиме реальной конкуренции, в то время как «производство» услуг в муниципальном управлении такого надежного индикатора оценки не имеет. Поэтому количественные показатели не просто абсорбируют в себя всю философию муниципального управления (цель, ценности, способы деятельности), но выступают источником образования особой нормативной системы, в рамках которой создается новая социальная реальность, потенциально способная прекратиться в имитационную. Угрозы этому мы видим в отсутствии надежных субъектов оценки качества муниципального управления из числа акторов, принимающих и реализующих управленческие решения.

Если имеет место работа на имитаџионные показатели, то можно поставить под сомнение достижение цели муниципального управления (повышение качества жизни населения муниципальных образований), пригодность используемых для этого ресурсов (как минимум, по линии физического и человеческого капитала) и разумность трат ресурсов (в связи с производством некачественных услуг). Иными словами, речь идет о недостижении реальной эффективности при формально «эффективном» управлении. Высказанное умозаключение предлагаем считать гипотезой, которая будет проверена в процессе проведения эмпирических исследований.

Далее мы переходим к завершающей части создания концепции - структурированию предметного пространства исследования. Это будет сделано посредством определения и описания менеджеристских инструменmoв, реализуемых для повышения эффективности муниципального управления. Именно их мы определяем в качестве эмпирических индикаторов, как когнитивные структуры, необходимые для разработки социологического инструментария и проведения эмпирических исследований. Мы можем предложить следующие формулировки указанных инструментов: 1) зависимость государственного финансирования от роста показателей социальноэкономического развития муниципального образования; 2) стимулирование предпринимательской активности в муниципальном управлении; 3) замена специалистов-управленцев эффективными менеджерами (институт сити-менеджмента).

1. Зависимость государственного финансирования от роста показателей соичальноэкономического развития муниципального образования. Применение этого инструмента осуществляется в формате выполнения взятых на себя обязательств, которые принято называть целевыми показателями развития. Органы муниципальной власти обязываются достичь запланированных показателей, масштаб которых символизирует высокий уровень эффективности муниципального управления. Здесь также применима обратная логика: неисполнение обязательств относительно целевых показателей приравнивается к управленческой неэффективности. В зависимости от институциональной сферы применения данного инструмента характер санкций может быть разный. В муниципальном управлении - увольнение сити-менеджера, потеря депутатского мандата на новых выборах, снижение финансирования. Муниципальные образования, которые имеют нормативно обоснованный потенциал роста социально-экономических показателей или демонстрируют устойчивый рост, получают грантовую поддержку от регионального бюджета. Эффективность деятельности ор- 
ганов власти местного самоуправления, подтверждение которой выступает основанием для финансового поощрения, рассчитывается по формулам, приведенным в Методических рекомендациях о выделении за счет бюджетных ассигнований из бюджета субъекта Российской Федерации грантов муниципальным образованиям в целях содействия достижению и (или) поощрения достижения наилучших значений показателей деятельности органов местного самоуправления городских округов и муниципальных районов (утв. Постановлением Правительства РФ от 17 декабря 2012 г. №1317).

2. Стимулирование предпринимательской активности в муниципальном управлении. В соответствии с действующим гражданским законодательством муниципальные органы власти могут быть субъектами предпринимательской деятельности. Это проявляется в виде оказания населению платных услуг, приватизации муниципального имущества, партнерства с коммерческими юридическими лицами, участия в инвестиционных проектах, предоставления муниципального имущества в аренду за плату. Для легализации этого права приняты и действуют соответствующие законы. Большая часть их была принята по аналогии с европейским законодательством еще до менеджеристской реформы в России. Между тем суть менеджеристского подхода, во всяком случае, как он сложился в западной традиции, сводится к тому, чтобы некоммерческие структуры, в том числе органы муниципального управления, действовали по подобию бизнес-организаций, что позволит им расширить бюджетные возможности за счет иных источников доходов, кроме местных налогов. Поэтому менеджеризм - это еще и идеология. Следовательно, в новых управленческих условиях от чиновника требуется мыслить категориями бизнесмена. Нормативным выражением этих инноваций стало принятие федерального закона от 13 июля 2015 г. №224-Ф3 «О государственно-частном партнерстве, муниципально-частном партнерстве в Российской Федерации и внесении изменений в отдельные законодательные акты Российской Федерации». По замыслу законодателя, данный ФЗ должен обеспечить сотрудничество местных органов власти и предпринимательских структур.
3. Замена специалистов-управленцев эфрфективными менеджерами (институт сити-менеджмента). Использование этого управленческого инструмента решает давний спор о том, кто должен заниматься управлением - менеджер или профессионал специалист, безоговорочно в пользу менеджера. С появлением профессии менеджера актуализируются ожидания, что он сможет принимать непопулярные решения, поощрять за заслуги, быть независимым от давления профессионального сообщества и свободным от субъективных пристрастий. Менеджерам приписывается не только знание управленческих навыков, но и особая социальная ответственность, готовность к принятию обязательств и моральной ответственности за исполняемое дело. В рамках менеджеристской парадигмы сложилось понятие «эффективный менеджер». Это управленец, работающий по контракту и принимающий на себя обязательства выполнить установленные в заключенном с ним договоре целевые показатели развития. Как правило, эффективные менеджеры не имеют определенного профиля деятельности и перемещаются в разных производственных сегментах. Карьерное движение вверх связывается со способностью достигать предзаданные целевые показатели развития. В муниципальном управлении этот новый порядок получил название «институт сити-менеджмента». Он связан с изменением нормативных условий легитимации вступления в должность главы муниципального образования. Отныне руководитель муниципалитета не избирается местным сообществом, a проходит многоступенчатую процедуру отбора, итог которой - заключение эффективного контракта между сити-менеджером и председателем местного парламента. Предполагается, что данный механизм вступления в должность приведет к профессионализации муниципального управления, что будет содействовать росту его эффективности.

Заключение. Подведем общий итог. Мы разработали методологический конструкт, нацеленный на исследование менеджеристских инструментов повышения эффективности муниципального управления. Он состоит из двух базовых элементов: методологических оснований и операционализации поня- 
тий. В основу методологической платформы положена теория рационального выбора Дж. Коулмана, которая, на наш взгляд, обладает необходимым потенциалом для обеспечения исследователя когнитивными ресурсами, чтобы полномасштабно изучить заявленное в названии статьи предметное поле. Сердцевиной методологии выступает идея о трех формах капитала - физического, человеческого и социального, которые в процессе выбора наиболее рациональной альтернативы социального действия трансформируются в набор ресурсов, используемых актором в качестве средства достижения цели. Второй элемент разработанного конструкта - операционализация понятий. После обоснования методологических принципов мы провели операции с такими понятиями, как «муниципальное управление», «эффективность муниципального управления», «государственный менеджеризм», «инструменты государственного менеджеризма в муниципальном управлении». В ходе операционализации была установлена внутренняя непротиворечивая связь между понятиями и выделены все необходимые их признаки, актуальные для структурирования предмета исследования. Решение указанной задачи позволило нам сформулировать количественно измеряемые эмпирические индикаторы, необходимые для разработки социологического инструментария. Предложены следующие формулировки: 1) зависимость государственного финансирования от роста показателей социальноэкономического развития муниципального образования; 2) стимулирование предпринимательской активности в муниципальном управлении; 3) замена специалистов-управленцев эффективными менеджерами (институт сити-менеджмента).

\section{Литература}

1. Коулман Дж. Капитал социальный и человеческий // Общественные науки и современность. - 2001. — №3. - С. 122-139.

2. Coleman S.J. The Asymmetrical Society. - Chicago, 1982. - $243 \mathrm{p}$.

3. Чихладзе Л. Т. Местное самоуправление в системе публичной власти в Российской Федерации // Вестник Московского университета МВД России. - 2017. — №3. - С. 171-174.
4. Газизова Л.И. К вопросу о разграничении понятий «муниципальная власть» и «местное самоуправление» // Власть. 2015. - №6. - С. 129-133.

5. Стальская А.С. Базовые подходы к управлению и их применение в известных компаниях // Вопросы экономики и управления. - 2016. - №5 (7). - С. 173-175.

6. Боровская М.А. Генезис муниципальной собственности и становление систем муниципального управления. - Таганрог, 2002. - C. 45-48.

7. Акулов А.О. Терминологические аспекты категорий «муниципальное управление» и «местное самоуправление» в теории и практике территориального управления // Известия Дальневосточного федерального университета. Экономика и управление. 2011. — №1. - C. 24-35.

8. Лангинен А.В. О соотношении понятий «местное управление», «местное самоуправление» и «муниципальное управление» / Ars Administrandi. Сборник статей. - Пермь: ПГУ, 2009. - С. 112-116.

9. Рикардо Д. Начала политической экономии и налогового обложения. - М.: Эксмо, 2007. - 960 c.

10. Пивоварова О.В. Анализ существующих подходов к оценке эффективности управления государственным имуществом: преимущества, недостатки, направления совершенствования // Российское предпринимательство. - 2017. - Т. 18. - №13. C. 2036-2048.

11. Евдокимова Т. В. Анализ генезиса теоретических подходов к понятию и оценке эффективности // Вестник Томского государственного университета. Экономика. 2013. - №3. - C. 22-27.

12. Денисов В.Т., Медведева Ю.П., Денисов Д.Д., Резник А.Е. Сущность эффективности и ее повышение // Поволжский торгово-экономический журнал. - 2010. №3. - C. 6-13.

13. Considine $M$. The corporate management framework as administrative science: a critique // Australian Journal of Public Administration. - 1988. - Vol. 47. — №1. - P. 7-15.

14. Aucoin P. Administrative Reform in Public Management: Paradigms, Principles, Paradoxes and Pendulums // Governance. 1990. - Vol. 3. - P. 116-128. 
15. Hood C. A Public Management for All Seasons? // Public Administration. - 1991. №69 (1). - P. 5-17.

\section{References}

1. Koulman Dzh. Kapital social'nyj i chelovecheskij [Social and human capital] // Obshhestvennye nauki i sovremennost' [Social Sciences and Modernity]. - 2001. - №3. - Pp. 122-139.

2. Coleman S.J. The Asymmetrical Society. - Chicago, 1982. - 243 p.

3. Chihladze L.T. Mestnoe samoupravlenie v sisteme publichnoj vlasti v Rossijskoj Federacii [Local self-government in the system of public power in the Russian Federation] // Vestnik Moskovskogo universiteta MVD Rossii [Bulletin of the Moscow University of the Ministry of Internal Affairs of Russia]. — 2017. №3. - Pp. 171-174.

4. Gazizova L.I. K voprosu o razgranichenii ponjatij «municipal'naja vlast'» $\mathrm{i}$ «mestnoe samoupravlenie» [On the issue of distinguishing the concepts of «municipal power» and «local self-government»] // Vlast' [Power]. — 2015. №6. - Pp. 129-133.

5. Stal 'skaja A.S. Bazovye podhody k upravleniju i ih primenenie $\mathrm{v}$ izvestnyh kompanijah [Basic approaches to management and their application in well-known companies] // Voprosy jekonomiki i upravlenija [Questions of economics and management]. — 2016. — №5 (7). Pp. 173-175.

6. Borovskaja M.A. Genezis municipal'noj sobstvennosti i stanovlenie sistem municipal'nogo upravlenija [The genesis of municipal property and the formation of municipal management systems]. - Taganrog, 2002. - Pp. 45-48.

7. Akulov A.O. Terminologicheskie aspekty kategorij «municipal'noe upravlenie» i «mestnoe samoupravlenie» $\mathrm{v}$ teorii i praktike territorial'nogo upravlenija [Terminological aspects of the categories «municipal management» and «local self-government» in the theory and practice of territorial management] // Izvestija Dal'nevostochnogo federal'nogo universiteta. Jekonomika i upravlenie [Proceedings of the Far Eastern Federal University. Economics and management]. — 2011. — №1. — Pp. 24-35.
8. Langinen $A . V$. O sootnoshenii ponjatij «mestnoe upravlenie», «mestnoe samoupravlenie» $\mathrm{i}$ «municipal'noe upravlenie» [On the correlation of the concepts of «local government», «local self-government» and «municipal management»] / Ars Administrandi. Sbornik statej [Ars Administrandi. Collection of articles]. Perm: PGU, 2009. - Pp. 112-116.

9. Rikardo D. Nachala politicheskoj jekonomii i nalogovogo oblozhenija [The beginning of political economy and tax taxation]. Moscow: Jeksmo, 2007. — 960 p.

10. Pivovarova $O . V$. Analiz sushhestvujushhih podhodov k ocenke jeffektivnosti upravlenija gosudarstvennym imushhestvom: preimushhestva, nedostatki, napravlenija sovershenstvovanija [Analysis of existing approaches to assessing the effectiveness of state property management: advantages, disadvantages, areas of improvement]// Rossijskoe predprinimatel'stvo [Russian entrepreneurship]. — 2017. - Vol. 18. №13. - Pp. 2036-2048.

11. Evdokimova T. V. Analiz genezisa teoreticheskih podhodov $\mathrm{k}$ ponjatiju i ocenke jeffektivnosti [Analysis of the genesis of theoretical approaches to the concept and evaluation of efficiency] // Vestnik Tomskogo gosudarstvennogo universiteta. Jekonomika [Bulletin of the Tomsk State University. Economy]. — 2013. — №3. Pp. 22-27.

12. Denisov V.T., Medvedeva Ju. P., Denisov D. D., Reznik A. E. Sushhnost' jeffektivnosti $i$ ee povyshenie [The essence of efficiency and its increase] // Povolzhskij torgovo-jekonomicheskij zhurnal [Volga Trade and Economic Journal]. - 2010. — №3. - Pp. 6-13.

13. Considine $M$. The corporate management framework as administrative science: a critique // Australian Journal of Public Administration. - 1988. - Vol. 47. - №1. - P. 7-15.

14. Aucoin P. Administrative Reform in Public Management: Paradigms, Principles, Paradoxes and Pendulums // Governance. 1990. - Vol. 3. - P. 116-128.

15. Hood C. A Public Management for All Seasons? // Public Administration. - 1991. №69 (1). - P. 5-17. 


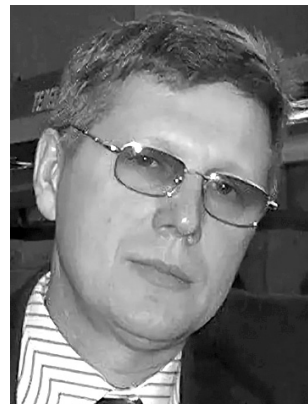

Дятлов Александр Викторович - доктор социологических наук, профессор Института социологии и регионоведения Южного федерального университета.

Dyatlov Alexander Viktorovich - Doctor of Sociological Sciences, Professor, Institute of Sociology and Regional Studies, Southern Federal University.

346500, г. Ростов-на-Дону, ул. Пушкинская, 160

160 Pushkinskaya st., 346500, Rostov-on-Don, Russia

E-mail: avdyatlov@yandex.ru

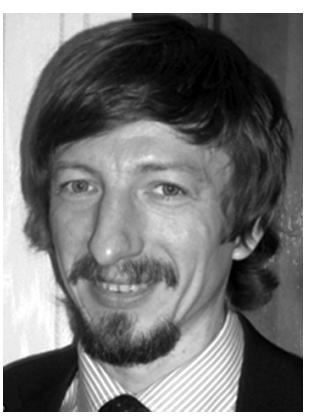

Ковалев Виталий Владимирович - доктор социологических наук, профессор Института социологии и регионоведения Южного федерального университета.

Kovalev Vitaliy Vladimirovich - Doctor of Sociological Sciences, Professor, Institute of Sociology and Regional Studies, Southern Federal University.

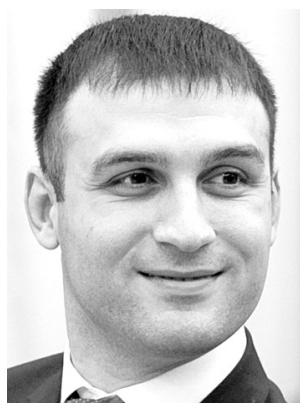

Асланов Яков Андреевич - кандидат социологических наук, доцент кафедры теоретической социологии и методологии региональных исследований Южного федерального университета, проректор по воспитательной работе и реализации молодёжных программ. Область научных интересов: гражданско-патриотическое воспитание, молодежная политика, межнациональные отношения, кавказоведение, гармонизация межнациональных отношений.

Aslanov Yakov Andreevich - Candidate of Sociological Sciences, Associate Professor of the Department of Theoretical Sociology and Methodology of Regional Studies of the Southern Federal University, Vice-rector for educational Work and implementation of youth programs. Research interests: civil and patriotic education, youth policy, interethnic relations, Caucasian studies, harmonization of interethnic relations. 